\title{
Target-Derived Neurotrophic Factors Regulate the Death of Developing Forebrain Neurons after a Change in their Trophic Requirements
}

\author{
R. Beau Lotto, Pundit Asavaritikrai, Leila Vali, and David J. Price \\ Genes and Development Group, Department of Biomedical Sciences, University Medical School, Edinburgh EH8 9XD, \\ United Kingdom
}

\begin{abstract}
Many neurons die as the normal brain develops. How this is regulated and whether the mechanism involves neurotrophic molecules from target cells are unknown. We found that cultured neurons from a key forebrain structure, the dorsal thalamus, develop a need for survival factors including brain-derived neurotrophic factor (BDNF) from their major target, the cerebral cortex, at the age at which they innervate it. Experiments in vivo have shown that rates of dorsal thalamic cell death are reduced by increasing cortical levels of BDNF and are increased in mutant mice lacking functional BDNF receptors or thalamocor-
\end{abstract}

tical projections; these experiments have also shown that an increase in the rates of dorsal thalamic cell death can be achieved by blocking BDNF in the cortex. We suggest that the onset of a requirement for cortex-derived neurotrophic factors initiates a competitive mechanism regulating programmed cell death among dorsal thalamic neurons.

Key words: brain-derived neurotrophic factor; cerebral cortex; programmed cell death; small eye mice; thalamus; Trk receptors
As the nervous system develops, many of its neurons die (Oppenheim, 1991). Although much is known about the biochemistry of the intracellular pathways that lead to programmed cell death by apoptosis, the mechanisms that initiate the process and regulate its rate are less well defined. A frequently proposed explanation for programmed cell death among developing neurons whose targets lie in the periphery is competition for limiting quantities of neurotrophic factors produced by their target cells (the neurotrophic hypothesis) (Oppenheim, 1991; Lucidi-Phillipi and Gage, 1993; Snider, 1994; Wright et al., 1997; Burek and Oppenheim, 1998; Pettmann and Henderson, 1998). Prominent among such factors are neurotrophins, nerve growth factor (NGF), brain-derived neurotrophic factor (BDNF), and neurotrophin 3 (NT3) and NT4, which act through high-affinity tyrosine kinase (Trk) receptors (NGF binds TrkA; BDNF and NT4 bind TrkB; and NT3 binds TrkA, TrkB, and TrkC) (Chao, 1992; Snider, 1994; Price and Willshaw, 2000). Competition between innervating neurons resulting in the death of those that are unsuccessful in gaining sufficient survival-promoting molecules may be a mechanism by which the numbers of cells in each structure are matched to the numbers in the target. Although the neurotrophic hypothesis has received support from work on motoneurons and peripheral neurons, for which the connectivity of groups of neurons is simpler than at higher levels, its applicability to the CNS has

\footnotetext{
Received Dec. 11, 2000; revised March 6, 2001; accepted March 15, 2001.

This research was supported by the Wellcome Trust, the Medical Research Council, and European Commission grants to D.J.P. and by a Thai Government scholarship to P.A. We thank Josette Carnahan and Amgen for anti-BDNF and anti-NT3 antibodies, David Shelton and Genentech for Trk-IgG molecules, Rudiger Klein and Bristol-Myers Squibb (Wallingford, CT) for trk knock-out mice, and Matt Kaufman for small eye mice.

R.B.L. and P.A. contributed equally to this work.

Correspondence should be addressed to Dr. David J. Price, Genes and Development Group, Department of Biomedical Sciences, Hugh Robson Building, University Medical School, George Square, Edinburgh EH8 9XD, UK. E-mail: dprice@ed.ac.uk.

Copyright (C) 2001 Society for Neuroscience $\quad 0270-6474 / 01 / 213904-07 \$ 15.00 / 0$
}

always been in doubt. The control of programmed cell death among neurons projecting to targets in the CNS is not understood, and it has been suggested that the mechanisms may be very different from those operating at lower levels (Lucidi-Phillipi and Gage, 1993; Snider, 1994; Pettmann and Henderson, 1998; Price and Willshaw, 2000).

Previous work has suggested that regulation of the extent and timing of programmed neuronal death in developing forebrain structures may involve neurotrophic molecules produced locally within each structure (Ghosh et al., 1994; Meyer-Franke et al., 1995; Magowan and Price, 1996; Lotto et al., 1997). Do developing forebrain neurons require neurotrophic molecules produced by more distant targets, as is the case in the peripheral nervous system? An answer to this question is crucial for assessing whether the essential elements of the neurotrophic hypothesis can be extrapolated to the highest levels of the developing nervous system. We studied the mechanisms regulating cell death in the developing dorsal thalamus, a pivotal forebrain structure that provides input to the sensory areas of the cerebral cortex. Thalamocortical axons begin to reach the cortex at approximately embryonic day 14 (E14) to E15 in the mouse (Lotto and Price, 1995; Molnar, 1998; Price and Willshaw, 2000). Previous studies have indicated that E15 dorsal thalamic neurons do not require interactions with the cortex to survive and that endogenous interactions mediated by any one of a number of neurotrophins may be adequate, suggesting redundancy among individual factors (Lotto et al., 1997). We examined how these requirements alter as the cells age.

\section{MATERIALS AND METHODS}

Culture methods. The region of the dorsal thalamus centered on the dorsal lateral geniculate nucleus (dlg) was identified and dissected as described previously (Rennie et al., 1994). Previous reports also describe in detail the dissociation and serum-free culture protocols (Lotto and Price, 1997; Lotto et al., 1997) and the fact that, under the conditions used here, almost all of the cells are neuronal and virtually none divide 

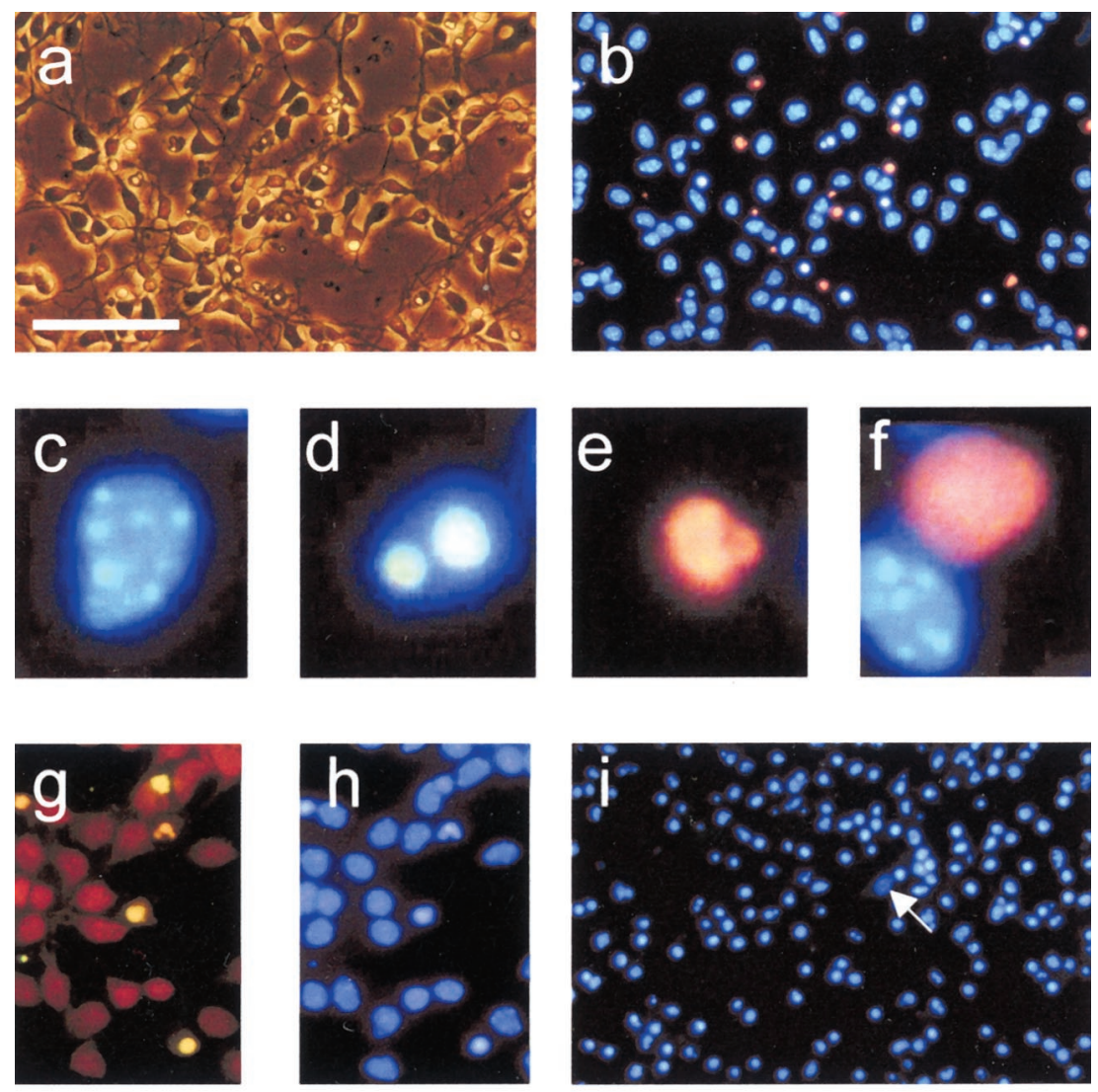

Figure 1. Illustrations of some of the main results of this study. $a$, Phase-contrast view of a high-density culture of E15 thalamic cells grown for $2 \mathrm{~d}$ in control medium showing many healthy neurons. $b$, Same field of view as in $a$, showing vital staining with bisbenzimide (blue) and propidium iodide (orange). The nuclei of most cells are healthy, showing diffuse staining with bisbenzimide; an example is shown in $c$. The nuclei of many of the cells that are phase-bright in $a$ show dense chromatin condensation (as exemplified in $d$ ), a feature associated with apoptosis (Kerr et al., 1972). Some of these cells contained propidium iodide, as shown in $e$, indicating disruption of their cell membranes (Rennie et al., 1994), a feature associated with late-stage apoptosis. Very rarely, cells contained propidium iodide without showing chromatin condensation, as illustrated in $f$, indicating death by necrosis. $g$, TUNEL-positive cells (yellow) in a high-density culture from an E15 thalamus after $5 \mathrm{~d}$ in CCM. $h$, Same field of view as in $g$ showing staining with bisbenzimide;
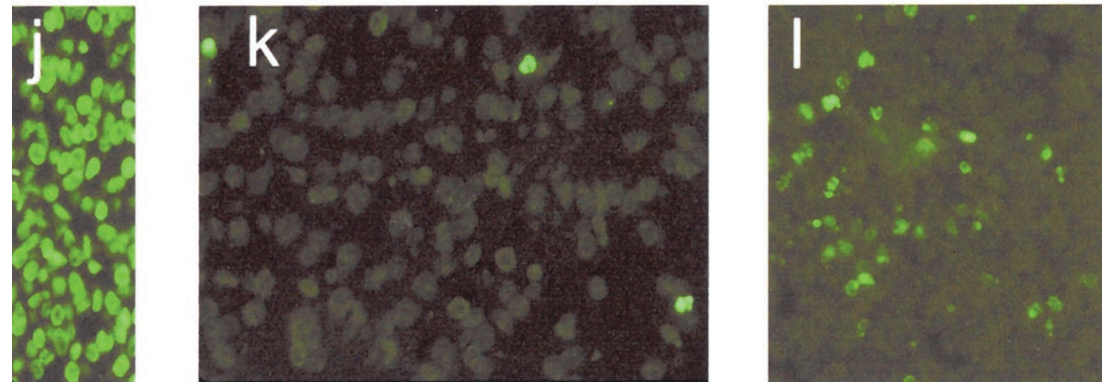
the TUNEL-positive cells have large, dense chromatin condensations. $i$, A high-density culture from an E15 thalamus after $5 \mathrm{~d}$ in control medium stained with bisbenzimide; most cells show chromatin condensation, and in this field of view, only one healthy cell is present (arrow). $j-l$, Identification of cell death in vivo using TUNEL. $j$, Control, TUNEL on a section of the thalamus of a P1 mouse pretreated with DNase; all cells are TUNEL-positive. $k$, Three TUNEL-positive cells in the thalamus of a P1 mouse. $l$, Many TUNEL-positive cells in the thalamus of an E19 Pax6-/- embryo. Scale bars: $a, b$, $i, j, 50 \mu \mathrm{m} ; g, h, k, l, 25 \mu \mathrm{m} ; c-f, 5 \mu \mathrm{m}$.

in the cultures (Lotto et al., 1997). Cell viability was determined as illustrated in Figure 1; terminal deoxynucleotidyl transferase-mediated biotinylated UTP nick end labeling (TUNEL) reactions were done as described previously (Gavrieli et al., 1992; Warren et al., 1999). In each culture, numbers of live and dead and/or dying cells in 10 randomly selected $0.2 \times 0.2 \mathrm{~mm}$ windows were counted blind across each of several wells to give percentages of viable neurons. Data from several independent cultures ( $n$ values are stated throughout) were averaged for statistical analyses.

Addition of substances to the cultures. Cortical conditioned medium (CCM) was obtained by dissecting the E19 cortex, sectioning it coronally at $300 \mu \mathrm{m}$ using a McIlwain tissue chopper, culturing the slices on Costar (Cambridge, MA) Transwell inserts (35 slices in $500 \mu$ l of medium) for 24 hr at $37^{\circ} \mathrm{C}$, and removing the medium, which was stored at $-20^{\circ} \mathrm{C}$. Control medium was also incubated for $24 \mathrm{hr}$ and stored at $-20^{\circ} \mathrm{C}$. After thalamic cells had been cultured for $3 \mathrm{~d}, 60 \mu \mathrm{l}$ of medium was removed and replaced with $70 \mu \mathrm{l}$ of either control medium or CCM and $10 \mu \mathrm{l}$ of PBS containing the protein kinase inhibitor K252a, one of the Trk-IgGs (Genentech, San Francisco, CA) (Shelton et al., 1995), anti-BDNF (Amgen, Thousand Oaks, CA) (Ghosh et al., 1994), turkey serum, one or more of the neurotrophins, or nothing (final concentrations are given with results). The extra volume replaced was to compensate for slight evaporation.

Western blots. CCM was concentrated 15-fold in a Vivaspin concentrator with a 5000 molecular weight cutoff filter (Vivascience, Lincoln, UK). Samples were run beside concentrated control medium and aliquots of pure neurotrophin at various concentrations, blotted, and probed with anti-neurotrophin antibodies (Santa Cruz Biotechnology, Santa Cruz, CA).

Analysis of programmed cell death in tissue sections. trkB-/- and trkC $-/-$ mice were identified by PCR (Klein et al., 1993, 1994); Pax6-/- mice were identified by phenotype (Warren and Price, 1997; Warren et al., 1999). TUNEL reactions (Fig. 1) were done on $10-\mu \mathrm{m}-$ thick sections as described previously (Gavrieli et al., 1992; Warren et al., 1999). Counts of TUNEL-positive cells were made blind with a $40 \times$ objective. All TUNEL-positive cells in every fifth section of the dlg or dorsal thalamus (the latter in Pax6-/- mice, in which individual thalamic nuclei are less clearly defined than normal) (Stoykova et al., 1996; Warren and Price, 1997) were counted and expressed as a number per 1000 cells counterstained with bisbenzimide or 4,6-diamidino-2phenylindole in the same regions of the same sections. In some brains, we also counted apoptotic cells identified on the basis of their densely condensed chromatin, as seen with the counterstaining. This method gave the same results as did TUNEL reactions, a point also illustrated for the in vitro results in Figure $1 g, h$.

In vivo injections. Single injections of BDNF or NT3 (10 ng in $1 \mu \mathrm{l}$ of PBS), anti-BDNF or anti-NT3 (1 $\mu$ l of a 1:12 dilution), or PBS $(1 \mu \mathrm{l})$ were made in the occipital cortex of postnatal day 2 (P2) wild-type mice anesthetized with halothane. Animals recovered for $24 \mathrm{hr}$ before being deeply anesthetized with sodium pentobarbitone ( $6 \mathrm{mg}$, i.p.) and perfused transcardially with $4 \%$ paraformaldehyde in PBS. Immunohistochemistry with anti-BDNF, anti-NT3, and anti-chicken (which cross- 
reacts with injected turkey antibodies) on sections of the cortex revealed injection sites of BDNF, NT3, and turkey antibodies (anti-BDNF and anti-NT3), respectively.

\section{RESULTS}

\section{Embryonic thalamic neurons develop a need for exogenous trophic factors}

We first tested the trophic requirements of developing dorsal thalamic neurons in vitro. Thalamic tissue centered on the dlg was dissected from E15 mice (Rennie et al., 1994), dissociated, and plated in serum-free medium (control medium) (Lotto and Price, 1997) at high plating density (4500 cells $\left./ \mathrm{mm}^{2}\right)$. As shown in previous work (Lotto and Price, 1997; Lotto et al., 1997), these methods yield cultures in which nearly all cells are neuronal. Immunocytochemistry revealed that $\sim 5 \%$ of these cells expressed GABA and were likely to be interneurons. We cultured the cells for $1-5 \mathrm{~d}$, recognized viable and nonviable neurons as shown in Figure $1 a-i$, and measured the percentages of viable neurons in each culture.

When control medium was used throughout, most neurons remained viable after $1-3 \mathrm{~d}$ in culture (Fig. 1a,b; see Fig. $3 a$ ), consistent with previous findings (Lotto et al., 1997), but most died after 4 and $5 \mathrm{~d}$, at ages equivalent to $\mathrm{E} 19$ and $\mathrm{P} 0$ in vivo (Fig. $1 i$; see Fig. $3 a$, broken line). A total of $87 \%$ of neurons remaining viable after $5 \mathrm{~d}$ were GABAergic, indicating preferential loss of projection neurons. Adding medium conditioned with E19 dorsal thalamic explants (using the same protocol as for cortical conditioned medium; see below) to these cultures did not maintain their viability; there was only on average $8.7 \pm 1.7 \%$ (SEM) survival at $5 \mathrm{~d}$ ( $n=15$ cultures). Similarly, when dorsal thalamic cells were obtained from E19 embryos and cultured for $24 \mathrm{hr}$, most died (see Fig. 3a, open circle). We conclude that, by the time dorsal thalamic neurons attain an age equivalent to E19, endogenous factors alone are no longer sufficient to maintain their viability in serum-free culture. This alteration appears to be regulated intrinsically because it takes place even when the cells are grown in isolation.

We tested whether E15 cells would survive longer if, on the third day of culture, we added medium preconditioned with E19 cerebral cortical slices. Under these conditions, most thalamic cells survived throughout their $5 \mathrm{~d}$ in culture (Fig. $1 g, h$; see Fig. $3 a$, solid line). In controls, viability was not maintained by adding an equivalent amount of unconditioned medium at $3 \mathrm{~d}$ (see Fig. $3 a$, broken line). In other experiments, although $<25 \%$ of dorsal thalamic cells obtained from E19 embryos and cultured for $24 \mathrm{hr}$ in unconditioned medium survived (see Fig. $3 a$, open circle), addition of CCM to the medium resulted in survival of $68.5 \pm 4.1 \%$ (SEM) of these cells. These results indicate that the major target of the dorsal thalamus can provide its neurons with essential trophic support that they fail to obtain endogenously as they age.

On the basis of these in vitro results, we predicted that dorsal thalamic cell death should increase late in gestation if thalamocortical connections are absent. Thalamocortical connections do not form in embryos homozygous for a mutation of the transcription factor Pax6, despite the presence of major forebrain structures, including the dorsal thalamus and cortex and many of their other axonal connections (Stoykova et al., 1996; Warren and Price, 1997; Kawano et al., 1999; Warren et al., 1999). Previous studies of Pax6-/- embryos aged E15 or less failed to detect changes in proportions of dead cells in the dorsal thalamus (Warren and Price, 1997). We examined two later ages, E17 and E19 (Pax6-/- newborns suffocate immediately after birth) using a

b
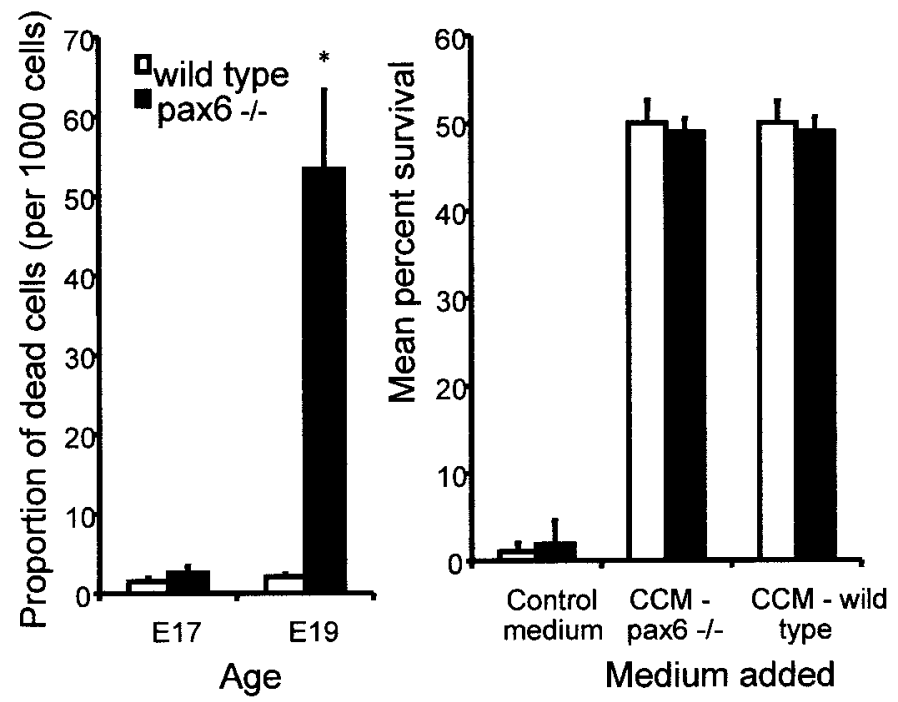

Figure 2. $a$, Mean \pm SEM proportions of dead cells (TUNEL positive) in the dorsal thalamus of wild-type and Pax6-/- embryos showing a significant increase in cell death in the mutants on E19 $\left({ }^{*} p<0.01 ; n=\right.$ 4-5 for each data point). $b$, Results of an in vitro analysis of Pax6-/thalamic cells. Survival of E15 wild-type and mutant cells after culture for $5 \mathrm{~d}$ at high density in control medium is shown; either CCM obtained from Pax $6-/-$ cortex or CCM obtained from wild-type cortex was added at $3 \mathrm{~d}$ ( $n=5$ for all data points). Both types of CCM rescued thalamic cells from both wild-types and mutants equally well. Open bars, Data from wild-type embryos $(a)$ or cells $(b)$. Filled bars, Data from Pax6-/embryos $(a)$ or cells $(b)$.

TUNEL (Fig. $1 j-l$ ). We detected no difference in the proportions of TUNEL-positive cells at E17 but observed a large increase at E19 in the mutants (Fig. 2a). Pax6 is not normally expressed in the body of the dorsal thalamus at E15 and older (Stoykova et al., 1996; Warren and Price, 1997), so it is unlikely that lack of functional PAX6 is directly responsible for increasing proportions of TUNEL-positive dorsal thalamic cells. As reported previously, proportions of dead cells do not increase in other regions of the E19 mutant forebrain, including the cerebral cortex (Warren et al., 1999), so increased proportions in the dorsal thalamus do not reflect a generalized loss of viability throughout the brain. We cultured E15 dorsal thalamic cells from wild-type or Pax6-/- embryos at high density for $5 \mathrm{~d}$, changing the medium for either control medium or medium conditioned with wild-type or Pax6-1- cortex at $3 \mathrm{~d}$. Hardly any wild-type or mutant thalamic cells survived in control medium, and both types of CCM rescued both types of cells to the same extent (Fig. 2b), indicating that mutant dorsal thalamic cells can respond normally to cortical factors and that mutant cortex has the ability to produce them. The most likely cause of increased death among late-gestation mutant dorsal thalamic cells is their failure to obtain cortical trophic support via thalamocortical connections.

\section{Target-derived BDNF contributes to the regulation of thalamic cell death}

As a first step in determining exogenous factors required by developing thalamic neurons, we applied the protein kinase inhibitor K252a, widely used as a selective blocker of the intracellular pathways activated by the neurotrophins (Tapley et al., 1992; Lotto et al., 1997), to thalamic neurons in vitro. As before, E15 dorsal thalamic neurons were cultured for $5 \mathrm{~d}$. K252a at $500 \mathrm{~nm}$ or 

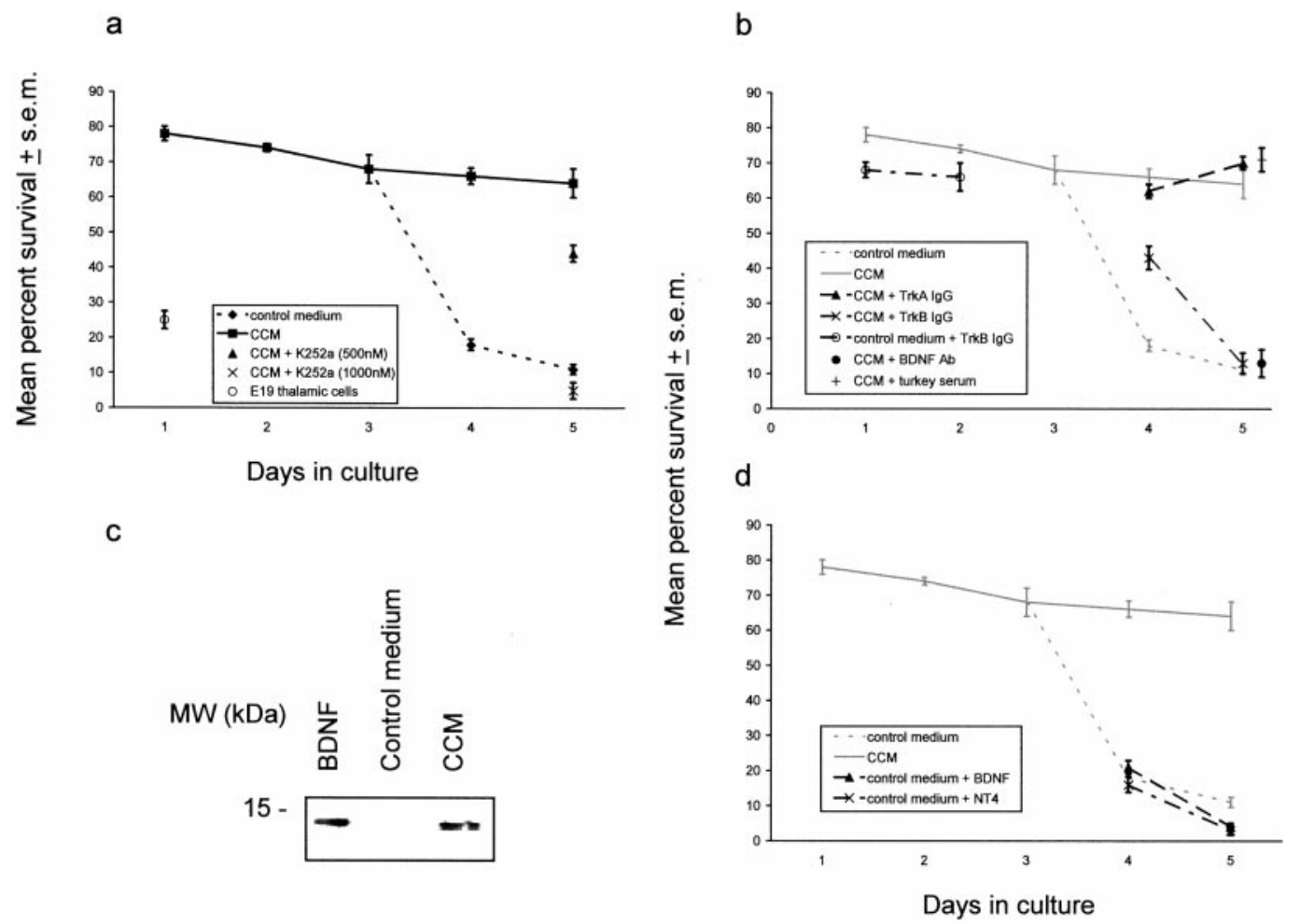

Figure 3. Results on changes in survival in culture. $a, b, d$, Graphs plot the mean percentages of thalamic cells surviving in high-density culture for 1-5 $\mathrm{d}$ under different conditions. $a$, Cells cultured from E15 in control medium throughout survived well until $3 \mathrm{~d}$, after which most died $(n=12,4,9,8$, and 12 cultures). Most cells from the E19 thalamus died after only $1 \mathrm{~d}$ (open circle; $n=4$ ). Addition of CCM on the third day rescued most cells cultured from E15 ( $n=8$ at day 4; $n=12$ at day 5$)$, and this effect was inhibited by 500 nM K252a and abolished by 1000 nM K252a $(n=4$ for each dose). Data in $a$ are reproduced in $b$ and $d$ for ease of comparison. $b$, TrkA-IgG or TrkB-IgG (38 $\mu \mathrm{g} / \mathrm{ml}$ final concentrations) was added to cultured E15 thalamic cells either from the outset of culture or with CCM after $3 \mathrm{~d}$. In the former case, viability was assessed at 1 and $2 \mathrm{~d}$ (open circles); in the latter case, viability was assessed at 4 and $5 \mathrm{~d}(n=8$ for each data point). TrkB-IgG inhibited the effect of CCM at $4 \mathrm{~d}$ and abolished it by $5 \mathrm{~d}$, whereas TrkA-IgG had no effect. TrkB-IgG caused only a small reduction in viability at 1 and $2 \mathrm{~d}$. Anti-BDNF (1:12 dilution, turkey polyclonal) added with CCM at $3 \mathrm{~d}$ also abolished the effect of CCM at $5 \mathrm{~d}$ ( filled circles), whereas addition of turkey serum with CCM at $3 \mathrm{~d}$ had no effect (symbols offset; $n=4$ each). $c$, Samples of concentrated CCM (right), control medium (middle), and pure BDNF at various concentrations (left) were run alongside each other, blotted, and probed with anti-BDNF antibodies. This example shows bands of similar intensity in the BDNF and CCM lanes, obtained when 10 ng of BDNF was run against $10 \mu \mathrm{l}$ of CCM. Because the CCM was concentrated 15 -fold for the Western blots, we estimated that the unconcentrated CCM contained $\sim 70$ $\mathrm{ng} / \mathrm{ml} \mathrm{BDNF}$. $d$, Control medium plus BDNF or NT4 (both $10 \mathrm{ng} / \mathrm{ml})$ was added after $3 \mathrm{~d}$, and cultures were examined after 4 or $5 \mathrm{~d}(n=8$ for each data point). Neither neurotrophin mimicked the effect of CCM.

$1 \mu \mathrm{M}$ (doses shown previously to have specific activity) (Tapley et al., 1992; Lotto et al., 1997) added with CCM on the third day of culture significantly reduced the viability of these neurons, as assessed 2 d later (Fig. 3a). These experiments implicated the neurotrophins in the continued survival of thalamic cells in the presence of CCM.

Additional experiments tested the roles of specific neurotrophin family members. The activities of TrkA or TrkB receptors were inhibited by adding TrkA-IgG or TrkB-IgG fusion proteins with CCM on the third day of culture (Shelton et al., 1995). These molecules produce specific inhibition by sequestering their corresponding ligands in the culture medium (Shelton et al., 1995). At 38 $\mu \mathrm{g} / \mathrm{ml}$, TrkB-IgG inhibited the survival-promoting effects of CCM on days 4 and 5 of culture (Fig. $3 b$ ); a lower dose, $8 \mu \mathrm{g} / \mathrm{ml}$, was not inhibitory (data not shown). In contrast, TrkA-IgG was ineffective, even at $38 \mu \mathrm{g} / \mathrm{ml}$ (Fig. $3 b$ ). TrkB-IgG at $38 \mu \mathrm{g} / \mathrm{ml}$ was added to the E15 cultures from the outset, and viability was assessed after 1 or $2 \mathrm{~d}$ in culture. Survival was only marginally reduced (Fig. 3b, open circles), indicating a redundancy of TrkB activity in E15 thalamic cells grown for up to $3 \mathrm{~d}$ in culture (consistent with our previous findings) (Lotto et al., 1997) and demonstrating that TrkB-IgG is not simply toxic. These results indicate that thalamic cells develop a requirement for activation of the $\operatorname{TrkB}$ receptor at an age equivalent to E18-E19.

We obtained a polyclonal anti-BDNF antibody known to block specifically the trophic effects of BDNF in culture (Ghosh et al., 1994) and added it or turkey serum (a control, because the antibody was raised in turkey), both diluted 1:12, with CCM on the third day of culture. Viability as determined $2 \mathrm{~d}$ later remained high in cultures with turkey serum alone but was very low in cultures containing the antibody (Fig. 3b). We confirmed the ability of the antibody to block BDNF in our hands as follows. Previous work has shown that most E15 thalamic cells grown for $2 \mathrm{~d}$ at low density $\left(1000\right.$ cells $\left./ \mathrm{mm}^{2}\right)$ die unless the medium is supplemented with neurotrophic factors such as BDNF (Lotto et al., 1997). We added BDNF (40 ng/ml final concentration) to E15 thalamic cells grown at low density for $2 \mathrm{~d}$ and confirmed a $138 \%$ increase in survival ( $p<0.01 ; n=4$ cultures with and without BDNF), which was prevented by adding anti-BDNF (1:12 dilution) with the BDNF $(n=4)$. To check that the antibody lacked nonspecific toxic effects, we added it (1:12 dilution) to E15 thalamic cells grown at high density $\left(4500\right.$ cells $\left./ \mathrm{mm}^{2}\right)$ for $2 \mathrm{~d}$ and found no significant effect on survival $(n=4$ cultures with and 
Figure 4. Effects of loss of Trk receptors and changing cortical BDNF levels in vivo. Graphs were obtained by counting TUNELpositive cells and TUNEL-negative cells (examples shown in Fig. $1 k, l)$ in a series of equally spaced sections. $a$, Mean \pm SEM proportions of dead cells in the wild-type, trk $C-1-$, and trkB-/- dlg in mice aged E15-P4 ( $n=3-5$ for each data point). Proportions increased with age and were significantly higher $(p<0.05)$ in $\operatorname{trkB}-1-$ mice than in wild-type and trkC-/- mice at E17, E19, and P1, as indicated (asterisks). $b, c$, The left and right occipital cortices in a section of a P3 mouse $24 \mathrm{hr}$ after an injection of $1 \mu \mathrm{l}$ of turkey anti-BDNF antibody into the right side $(c)$, reacted with a biotinylated antichicken antibody (which cross-reacts with turkey antibody) to reveal the injection site. Diffuse staining of the cortical neuropil $(c)$ suggested diffusion of up to $\sim 1 \mathrm{~mm}$ around the injection site. Scale bar, $100 \mu \mathrm{m}$. $d$, Mean \pm SEM proportions of dead cells in the dlg after injections into the cortex on P2 $(n=$ 4 for all data points); BDNF and anti-BDNF caused significant changes compared with the saline controls $\left({ }^{*} p<0.01\right)$.

without antibody). These results indicated that thalamic cells developed a requirement for BDNF after $3 \mathrm{~d}$.

Previous studies have shown that, during the last week of gestation, the embryonic cortex contains mRNA for BDNF (Maisonpierre et al., 1990; Behar et al., 1997). Western blots detected BDNF but not other neurotrophins in CCM, indicating that the cortex may be a potent source of the BDNF required by developing thalamic cells. We estimated that the CCM added to the cultures would provide BDNF at a final concentration of $\sim 50$ $\mathrm{ng} / \mathrm{ml}$ (Fig. $3 c$ ). We added pure BDNF and other neurotrophins at $3 \mathrm{~d}$, either singly or in various combinations, at a wide range of doses including $50 \mathrm{ng} / \mathrm{ml}$ and covering those known to be effective in other systems and in thalamic cells at earlier ages (Lotto et al., 1997). None was effective in increasing viability above that seen with control medium at 4 and $5 \mathrm{~d}$. Examples of these results are shown in Figure $3 d$, for BDNF and NT4. As a control, we confirmed that the neurotrophins used in these experiments were active by showing in parallel experiments that they caused a significant increase in the viability of E15 thalamic cells grown at low plating density for 1-2 d (Lotto et al., 1997). These results indicate that, although BDNF becomes essential, it is insufficient for the survival of thalamic cells at an age equivalent to E18-E19. Thalamic cells start to require BDNF as well as other factors that are present in CCM at approximately this time. In contrast, in younger thalamic cells, activation of TrkB is not an absolute requirement, and BDNF or any of the other neurotrophins are sufficient for the survival of most dorsal thalamic cells (Lotto et al., 1997).

We sought supporting evidence for our in vitro results from a series of in vivo experiments. First, we hypothesized that in mice lacking functional TrkB receptors we might see at least some evidence for increased cell death among dorsal thalamic cells during the days after E15, even allowing for the caveats outlined in Discussion. We examined the dlg because dissections for the in vitro work were centered on it (Rennie et al., 1994), it is well defined even in the embryonic brain, and it is known to express high levels of TrkB throughout this period (Ringstedt et al., 1993; Allendoerfer et al., 1994; Lotto et al., 1997) (confirmed with our own in situ hybridizations; data not shown). We measured proportions of TUNEL-positive cells, as illustrated in Figure $1 j-l$, in sections through the dlg of wild-type mice and mice homozygous for targeted mutations of sequences encoding the catalytic domains of the TrkB or TrkC receptors (trkB-/- or trkC-/-) (Klein et al., 1993, 1994). In wild-type embryos, proportions of dead cells in the dlg increased with age, most sharply just after birth (Fig. 4a), compatible with previous findings (Spreafico et al., 1995; Alcántara et al., 1997). In trkB-/- embryos, proportions of dead cells were not different from wild-types at E15 but were significantly elevated at E17-P1 (Fig. 4a). The proportional increase over wild-types was greatest at E17 and less at E19 and P1. There was no significant difference from wild types at P4. In 
trkC-/- embryos, proportions of dead cells were no different from wild types at all of the ages studied (Fig. 4a). trkB-/- and trkC-/- mice die at approximately P7 (Alcántara et al., 1997), but the transient nature of the effect in $\operatorname{trk} B-/-$ mice and the lack of effect in trkC-/- mice argue against the effect in $\operatorname{trk} B-/-$ mice being a nonspecific result of increasing poor health. The lack of an effect in the trkB-/- embryos at E15 is compatible with our culture results, suggesting redundancy of TrkB and BDNF at these early times.

We then examined the effects of injecting various neurotrophins or neurotrophin blockers into the occipital cortex of P2 mice. Figure $4 c$ illustrates the appearance of the injection sites (revealed immunohistochemically), in this case of anti-BDNF 24 hr after administration. By comparing immunostaining in the neuropil on the injected and uninjected sides (Fig. 4b), we estimated that substances spread through the cortex by up to $1 \mathrm{~mm}$. Proportions of dead cells in the dlg after injections of saline, NT3, or anti-NT3 (Fig. 4d) were similar to those found in wild-type mice of comparable age (Fig. $4 a$ ). Injections of BDNF or antiBDNF produced significantly lower and higher proportions, respectively (Fig. 4d). This finding indicates that altering the access of dlg neurons to BDNF in the occipital cortex can regulate their death rates.

\section{DISCUSSION}

Previous work has indicated that, at the age at which dorsal thalamic neurons start to innervate the cerebral cortex, they interact with each other to promote their own survival and that this interaction requires signaling through neurotrophin receptors (Lotto et al., 1997). Early dorsal thalamic cells are promiscuous, however, producing and responding to NGF, BDNF, NT3, and NT4 (Lotto et al., 1997). In line with these findings, our present results indicate a redundancy of BDNF and of activation of the TrkB receptor at young ages. Addition of TrkB-IgG or BDNF blocking antibody in vitro or the absence of TrkB receptors in vivo had little effect on the viability of E15 dorsal thalamic neurons, presumably because other neurotrophins covered for the specific loss. One of our major new findings is that dorsal thalamic neurons are programmed to change their trophic requirements as they age. One component of this change is to a requirement for BDNF. This change is different from the types of switching of neurotrophin requirements seen in the peripheral nervous system (Davies, 1997). Trigeminal, vestibular, and nodose neurons are all initially neurotrophin independent but become dependent on one or two specific neurotrophins; trigeminal neurons later switch from dependency on BDNF and NT3 to dependency on NGF (Davies, 1997). The purpose of these peripheral changes is unclear (Davies, 1997). For dorsal thalamic neurons, the onset of more stringent survival requirements may precipitate a competition for BDNF with the removal of dependent cells unable to obtain enough of this factor. This may induce the observed increase in dorsal thalamic cell death normally seen shortly after the change (Fig. $4 a$, wild-type data).

Our findings indicate that the source of the BDNF on which dorsal thalamic neurons become dependent is most likely the cerebral cortex and that BDNF is not the only cortex-derived factor required. Thus, conditions are established under which competition between thalamic cells for target-derived trophic factors may occur. Increasing or decreasing the availability of BDNF in the cortex influences the proportion of cells in the dorsal thalamus that die, suggesting that such a competition may be an important mechanism regulating cell numbers.
Although our experimental evidence for this focuses on the occipital cortex and dlg, it is likely that this conclusion applies to other cortical areas and to dorsal thalamic nuclei, which also express BDNF and TrkB.

Our evidence points to the importance of target-derived factors, including BDNF, in regulating cell death in the developing dorsal thalamus. This is in agreement with previous findings that occipital lesions in newborn rats cause cell death among dlg neurons and that this death can be countered by administering diffusible proteins from the developing cortex to the lesion site (Cunningham et al., 1987; Eagleson et al., 1992). There remains an issue of what proportion of dorsal thalamic cells become dependent on BDNF. Our culture results suggest that the majority of dorsal thalamic cells do become dependent. This observation is in contrast to the observation from our work and that of Alcántara et al. (1997) that death rates in the dlg in $t r k B-/-$ mice are not sufficient to obliterate this structure, as might have been predicted from our in vitro results. It is a strong possibility that the knock-out results underestimate the numbers of neurons that become dependent on BDNF during the development of normal mice. It is widely recognized that conventional knock-outs of neurotrophins and their receptors in vivo show less neuronal loss in the CNS than would be predicted from in vitro analyses (Snider, 1994; Pettmann and Henderson, 1998). Why this occurs is not clear. One hypothesis is that the loss of one factor throughout the preceding stages of development produces a compensatory increase in the activity of other pathways. In the system that we have studied, the absence of TrkB signaling among developing dorsal thalamic neurons before the narrowing of their neurotrophin requirements may minimize the impact of a lack of TrkB signaling at the time of the change. For example, as the mutant neurons move out of their promiscuous phase to develop a requirement for BDNF, they may quickly skip to using a different neurotrophin instead. It seems highly plausible that they would have a reduced tendency to narrow to a pathway that has not existed during their promiscuous phase. Such a possibility might explain why the greatest proportional increase in dead cells in the dorsal thalamus of $\operatorname{trk} B-/-$ mice was seen right at the start of the switching period predicted from in vitro results (in fact, it was slightly earlier than predicted, although such precise comparisons are of dubious significance given the variations between the experimental paradigms) and why this increase dwindled over the following days. Given these considerations, it is not difficult to see why the results from in vitro work with normal cells appear to contrast quantitatively, although not qualitatively, with those from the trkB-/- mice. Certainly, the lesser effect in the mutants does not imply that BDNF does not play a crucial role in the survival of a large proportion of dorsal thalamic neurons during normal development.

Relevant to the above discussion is the observation that the effect of acute blockade of BDNF in the cortex of normal mice was quantitatively greater than the effect in the $t r k B-/-$ mice. These experiments were done several days after the switch to a requirement for BDNF was predicted to have occurred, when the expectation would be that the system would have little chance to compensate for the block. Clearly, we do not know the efficiency of the antibody block, but it is likely to have been less complete than the total dissociation between the dorsal thalamus and the cortex that occurs in the Pax6-/- mice. In these mutants, we observed greater proportions of TUNEL-positive cells than in any of the other in vivo experiments, presumably because all target-derived trophic support is removed, which is unlikely with 
the other paradigms. Given that the clearance of dead cells is known to be rapid in vivo and may take as little as several hours (Barres et al., 1992), the high proportions of TUNEL-positive cells in sections of the thalamus of E19 Pax6-/- mutants likely reflect a very high rate of cell loss. This might obliterate the structure within a few days if it were not for the fact that the mutant mice die first. Taking all of our results together, we conclude that a very high proportion of dorsal thalamic neurons become dependent on target-derived cortical trophic factors for their survival late in embryogenesis. Furthermore, during normal development, most of these cells become dependent on a supply of BDNF, which is obtained from the cortex.

In the developing brain, neurotrophins have important roles in the refinement of dendritic arbors and axonal connections and in the regulation of neuronal plasticity (McAllister et al., 1995; Ghosh, 1996; Huang et al., 1999), but their roles as survival factors have been less clear. Our results indicate an important role for target-derived factors, including BDNF, in regulating survival in the developing brain.

\section{REFERENCES}

Alcántara S, Frisén J, del Río JA, Soriano E, Barbacid M, Silos-Santiago I (1997) TrkB signaling is required for postnatal survival of CNS neurons and protects hippocampal and motor neurons from axotomyinduced cell death. J Neurosci 17:3623-3633.

Allendoerfer KL, Cabelli RJ, Escandon E, Kaplan DR, Nikolics K, Shatz CJ (1994) Regulation of neurotrophin receptors during the maturation of the mammalian visual system. J Neurosci 14:1795-1881.

Barres BA, Hart IK, Coles HSR, Burne JF, Voyvodic JR, Richardson WD, Raff MC (1992) Cell death and control of cell survival in the oligodendrocyte lineage. Cell 70:31-46.

Behar TN, Dugich-Djordjevic MM, Li YX, Ma W, Somogyi R, Wen X, Brown E, Scott C, McKay RDG, Barker JL (1997) Neurotrophins stimulate chemotaxis of embryonic cortical neurons. Eur J Neurosci 9:2561-2570.

Burek MJ, Oppenheim RW (1998) Cellular interactions that regulate programmed cell death in the developing vertebrate nervous system. In: Cell death and diseases of the nervous system (Koliatsos V, Ratan R, eds), pp 223-246. Totowa, NJ: Humana.

Chao MV (1992) Neurotrophin receptors: a window into neuronal differentiation. Neuron 4:583-593.

Cunningham TJ, Haun F, Chantler PD (1987) Diffusible proteins prolong survival of dorsal lateral geniculate neurons following occipital cortex lesions in newborn rats. Dev Brain Res 37:133-141.

Davies A (1997) Neurotrophin switching: where does it stand? Curr Opin Neurobiol 7:110-118.

Eagleson KL, Cunningham TJ, Haun F (1992) Rescue of both rapidly and slowly degenerating neurons in the dorsal lateral geniculate nucleus of adult rats by a cortically derived neuron survival factor. Exp Neurol $116: 156-162$

Gavrieli Y, Sherman Y, Ben-Sasson SA (1992) Identification of programmed cell death in situ via specific labeling of nuclear fragmentation. J Cell Biol 119:493-501.

Ghosh A (1996) Cortical development: with an eye on neurotrophins. Curr Biol 6:130-133.

Ghosh A, Carnahan J, Greenberg ME (1994) Requirement for BDNF in activity-dependent survival of cortical neurons. Science 263:1618-1623.

Huang ZJ, Kirkwood A, Pizzorusso T, Porciatti V, Morales B, Bear MF, Maffei L, Tonegawa S (1999) BDNF regulates the maturation of inhibition and the critical period of plasticity in mouse visual cortex. Cell 98:739-755.

Kawano H, Fukuda T, Kubo K, Horie M, Uyemura K, Takeuchi K, Osumi N, Eto K, Kawamura K (1999) Pax-6 is required for thalamocortical pathway formation in fetal rats. J Comp Neurol 408:147-160.

Kerr JFR, Wyllie AH, Currie AR (1972) Apoptosis: a basic biological phenomenon with wide-ranging implications in tissue kinetics. $\mathrm{Br} \mathrm{J}$ Cancer 26:239-257.

Klein R, Smeyne RJ, Wurst W, Long LK, Auerbach BA, Joyner AL, Barbacid M (1993) Target disruption of the trkB neurotrophin receptor gene results in nervous system lesions and neonatal death. Cell 75:113-122.

Klein R, Silos-Santiago I, Smeyne RJ, Lira SA, Brambilla R, Bryant S, Zhang L, Snider WD, Barbacid M (1994) Disruption of the neurotrophin 3 receptor gene trkC eliminates 1a muscle afferents and results in abnormal movement. Nature 368:249-251.

Lotto RB, Price DJ (1995) The stimulation of thalamic neurite outgrowth by cortex-derived growth factors in vitro: the influence of cortical age and activity. Eur J Neurosci 7:318-328.

Lotto RB, Price DJ (1997) Thalamus: dispersed neuron culture. In: The neuron in culture. International Brain Research Organization handbook series: methods in the neurosciences (Haynes LW, ed), pp 525530. Chichester, UK: Wiley.

Lotto RB, Clausen JA, Price DJ (1997) Endogenous neurotrophins promote the survival of embryonic thalamic neurons. Eur $\mathrm{J}$ Neurosci 9:1940-1949

Lucidi-Phillipi CA, Gage FH (1993) The neurotrophic hypothesis and the cholinergic basal forebrain projection. Prog Brain Res 98:241-249.

Magowan G, Price DJ (1996) Trophic and outgrowth-promoting effects of $\mathrm{K}^{+}$-induced depolarization on developing thalamic cells in organotypic culture. Neuroscience 74:1045-1057.

Maisonpierre PC, Bellescio L, Friedman B, Alderson RF, Wiegand SJ, Furth ME, Lindsay RM, Yancopoulos GD (1990) NT-3, BDNF, and NGF in the developing rat nervous system: parallel as well as reciprocal patterns of expression. Neuron 5:501-509.

McAllister AK, Lo DC, Katz LC (1995) Neurotrophins regulate dendritic growth in developing visual cortex. Neuron 15:791-803.

Meyer-Franke A, Kaplan MR, Pfrieger FW, Barres BA (1995) Characterization of the signaling interactions that promote the survival and growth of developing retinal ganglion cells in culture. Neuron 15:805-819.

Molnar Z (1998) Development of thalamocortical connections. Berlin: Springer.

Oppenheim RW (1991) Cell death in the nervous system. Annu Rev Neurosci 14:453-501.

Pettmann B, Henderson CE (1998) Neuronal cell death. Neuron 20:633-647.

Price DJ, Willshaw DA (2000) Mechanisms of cortical development. Oxford: Oxford UP.

Rennie S, Lotto RB, Price DJ (1994) Growth-promoting interactions between the murine neocortex and thalamus in organotypic co-cultures. Neuroscience 61:547-564

Ringstedt T, Lagercrantz H, Persson H (1993) Expression of members of the trk family in the developing postnatal rat-brain. Dev Brain Res $72: 119-131$.

Shelton DL, Sutherland J, Gripp J, Camerato T, Armanini MP, Phillips HS, Carroll K, Spencer SD, Levinson AD (1995) Human Trks: molecular cloning, tissue distribution, and expression of extracellular domain immunoadhesions. J Neurosci 15:477-491.

Snider WD (1994) Functions of the neurotrophins during nervous system development: what the knockouts are teaching us. Cell 77:627-638.

Spreafico R, Frassoni C, Arcelli P, Selvaggio M, Debiasi S (1995) In situ labeling of apoptotic cell death in the developing cerebral cortex and thalamus of rats during development. J Comp Neurol 363:281-295.

Stoykova A, Fritsch R, Walther C, Gruss P (1996) Forebrain patterning defects in Small eye mutant mice. Development 122:3453-3465.

Tapley P, Lamballe F, Barbacid M (1992) K252a is a selective inhibitor of the tyrosine protein-kinase activity of the trk family of oncogenes and neurotrophin receptors. Oncogene 7:371-381.

Warren N, Price DJ (1997) Roles of Pax-6 in murine diencephalic development. Development 124:1573-1582.

Warren N, Caric D, Pratt T, Clausen JA, Asavaritikrai P, Mason JO, Hill RE, Price DJ (1999) The transcription factor, Pax6, is required for cell proliferation and differentiation in the developing cerebral cortex. Cereb Cortex 9:627-635.

Wright DE, Zhou L, Kucera J, Snider WD (1997) Introduction of a neurotrophin-3 transgene into muscle selectively rescues proprioceptive neurons in mice lacking endogenous neurotrophin-3. Neuron 19: 503-517. 